\title{
Education
}

\section{Preparing for Your First Job: A Resident's Outline to Curriculum Vitae Writing}

Marissa Bournique, $\mathrm{DO}^{1}$

\section{Abstract}

Author affiliations are listed at the end of this article.

Correspondence to: Dr. Marissa Bournique, DO Largo Medical Center 20114 th St. SW Largo, FL 33770 (marissa.bournique@gmail. com)

\section{Keywords}

job application; professionalism; career mobility; employment; writing; curriculum vitae

Residents are no strangers to writing a resume. At this point in their careers, residents will likely have written at least three prior versions for college, medical school, residency and/or fellowship, along with the added possibility of applications to Master's programs. Yet, for some residents this may be the initial compilation of a curriculum vitae (CV)-the document highlighting the culmination of their academic-medical career and initial step towards seeking their first job as a full-fledged physician.

"Curriculum vitae" is Latin for "course of life" and that definition alone highlights the major difference between a resume a CV (Tomaszewski, 2019). The intention of a CV is to showcase details about an applicant's education, professional career, research, and other achievements. A resume on the other hand is French for "to sum up" and is a much more abbreviated version of self-summary, typically limited to one to two pages in length.

The accomplishments of a medical professional in training should not be sold short due to poor recall. Just like in medical records-if it wasn't documented, it didn't happen. After eight years of higher education and three to eight years of medical training, it becomes very difficult to re- member all of the details. Therefore, the most important consideration and first step when beginning to format a $\mathrm{CV}$ is to keep an accurate and up-to-date log of one's accomplishments and activities throughout their academic and medical career. A good starting point for many job seekers will be their residency application. Residents should set calendar reminder dates to periodically update their CV-perhaps every six to nine months. At the completion of training this document will have a large amount of excess information but trimming the fat is always easier than reconstructing the pig.

Formatting is step two in the process and begins when writing the first formal draft. Applicants should select an organized, accurate and professional format that allows employers to quickly identify personal information and avoid confusion. Traditional fonts, such as Arial, Calibri and Times New Roman, are recommended at font size 11 or 12. Headings should be clear, in bold, and/or a larger type size, and in a uniform format throughout the document. Information should be written chronologically with the most recent position first and using a consistent date format throughout (ex. January 2015 - February 2019 or 1/2015 - 2/2019). ${ }^{2}$

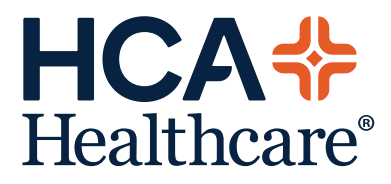

www.hcahealthcarejournal.com

(C) 2020 HCA Physician Services, Inc. d/b/a Emerald Medical Education
HCA Healthcare Journal of Medicine 
An article released in Time magazine found that recruiters spend an average of six seconds reviewing resumes-that was seconds, not minutes. ${ }^{3}$ Another article suggested a more generous 30 seconds of review. ${ }^{4}$ The point is that no one wants to lose a job opportunity due to confusion with an application. Unique formatting is not the appropriate tactic to make a CV stand out. Applicants must ensure that readers are easily able to identify multiple points of contact: name, accurate phone number, mailing address and e-mail address. A voicemail box should be set up to allow messages to be received and have an appropriate outbound message. Also, residents should ensure that the email address provided is professional, for example, beachbum2020@***.com does not promote the image of a hardworking candidate. Consideration should be given to creating a separate e-mail address during the career search in order to prevent loss of important contacts which can occur after departure from an academic institution. This will also decrease the amount of spam mail to monitor after completion of the job search.

When structuring a $\mathrm{CV}$, a resident should consider the type of job which is being sought-the structure for an academic position will be significantly different than for a private practice or hospital position. A CV written for a private practice or hospital position should be limited to a cover letter and an additional one to two pages of pertinent content with an emphasize on one's medical career. Those targeting an academic position should place emphasis on research accomplishments, including posters, presentations and publications, with detailed information regarding dates of presentations and references for publications. Academic CVs tend to be slightly longer, with an average of three pages and a maximum of five pages. ${ }^{2,5}$

Cover letters seem to be less heavily standardized within the medical community, however studies suggest that nearly $50 \%$ of recruiters felt them to be beneficial and others mentioned that applications felt incomplete without one. ${ }^{6}$ The purpose of the cover letter is to provide additional depth of personalization to an application and should be customized for each job. Candidates should highlight their strengths and a commitment to that particular area, group or practice setting. Take this time to incorporate personal information and tie this in to learned facts about the target organization. This can also be the place to provide a brief explanation of any gaps within a CV which may otherwise raise questions. The cover letter should be no more than three or four paragraphs and be addressed to a specific person rather than "To Whom It May Concern", if this information is available. ${ }^{6}$

Proofreading the $\mathrm{CV}$ will be key to a job candidate's success. Residents should ask a mentor, program director and co-residents to read the final version prior to submission. This is especially important if English is not the candidate's primary language.

\section{Curriculum Vitae Checklist}

- Cover letter: Personalize the message while also maintaining a professional tone. Complete background research on the group, practice or location, then demonstrate that knowledge within the letter.

- Name and contact information: Make sure it is up-to-date and easily identifiable by centering it at the top of the page and including full name, appropriate suffix, home address, e-mail address and/or phone contact information. The voice mailbox should be checked and cleared often so as not to miss any call-backs. Monitor the junk e-mail folder for communications from potential employers.

- Education and training: Include location along with start and finish dates for each step in one's academic career: undergradvate, medical school, Master's degree, internships, residencies, and fellowships.

- Licensure/Certification: List board certifications, board eligibility and dates obtained. Include dates of ACLS/BLS if desired.

- Professional and teaching experience (medicine-related only): List procedures which have been performed and patient volumes, if applicable to the specialty.

- Activities and committee memberships: Include roles and responsibilities held and brief descriptions of associated accomplishments.

- Honors, prizes and awards: Typically, this 
should be focused on medical accomplishments but can include awards that also highlight character or personal accomplishments if content is sparse.

- Publications, presentations and invited speaking engagements: This should primarily be focused on medically relevant roles. Include location if the speaking engagement was at a conference or seminar.

- Research experience: A major component to academic job applications, a complete list of research accomplishments and publications is necessary for academic positions.

- Optional content:

- Professional photograph: This is a feature that gets mixed reviews from different resources. ${ }^{2,4}$ If a photograph is included it should be professional, such as a headshot from a resident training facility.

- Personal interests and hobbies: This should be brief; only include interests that aren't potentially objectionable to an employer. Some resources suggest including the reason for each interest or hobby as a way to reveal personality as opposed to just a list. ${ }^{5}$

- Character references: References are usually requested at a later date, usually as a separate submission and are not essential in the $\mathrm{CV}$. $^{2}$

\section{Additional Resources}

http://businesssideofmedicine.com/contact/ https://www.nejmcareercenter.org/article/creating-a-physician-cv-that-shines/ https://www.nejmcareercenter.org/article/96/ writing-compelling-physician-cover-letters/ https://www.practicewithus.com https://www.acponline.org/about-acp/ about-internal-medicine/career-paths/residency-career-counseling/guidance/types-of-medical-practices

https://www.nejmcareercenter.org/article/96/ writing-compelling-physician-cover-letters/

\section{Conflicts of Interest}

The author declares she has no conflicts of interest.

Dr. Marissa Bournique is an employee of Largo Medical Center, a hospital affiliated with the journal's publisher.

This research was supported (in whole or in part) by HCA Healthcare and/or an

HCA Healthcare affiliated entity. The views expressed in this publication represent those of the author(s) and do not necessarily represent the official views of HCA Healthcare or any of its affiliated entities.

\section{Author Affiliation}

1. Largo Medical Center, Largo, FL

\section{References}

1. Tomaszewski M. The Difference Between a CV vs a Resume Explained. zety. https://zety.com/ blog/cv-vs-resume-difference. Published November 22, 2019. Accessed December 9, 2019.

2. Darves B. Creating a Physician CV That Shines. NEJM CareerCenter. https://www.nejmcareercenter.org/article/creating-a-physician-cvthat-shines. Published August 7, 2018. Accessed December 9, 2019.

3. Sanburn J. How to Make Your Resume Last Longer Than 6 Seconds. Time. https://business.time. com/2012/04/13/how-to-make-your-resumelast-longer-than-6-seconds/. Published April 13, 2012. Accessed December 9, 2019.

4. Carrington College. How to Build a Strong Medical Resume. TopResume. https://www. topresume.com/career-advice/how-to-build-astrong-medical-resume. Published July 19, 2016. Accessed February 2, 2020.

5. Agha R, Whitehurst K, Jafree D, Devabalan Y, Koshy K, Gundogan B. How to write a medical CV. Int J Surg Oncol (N Y). 2017;2(6):e32. https:// doi.org/10.1097/IJ9.0000000000000032

6. Santiago AC. Do You Need to Send a Cover Letter When Applying for a Medical Job? Verywell Health. https://www.verywellhealth.com/whenyou-need-to-send-a-cover-letter-with-yourcv-1736050. Updated February 6, 2020. Accessed December 9, 2019. 